First publ. in: Theories of social psychology / Lange, Paul A. van (Ed.). - Los Angeles [u.a.] : Sage, 2012. - pp. 526-545. - (Handbook of theories of social psychology ; 1). - ISBN 978-0-85702-960-7

\title{
Mindset Theory of Action Phases
}

\author{
Peter M. Gollwitzer
}

\begin{abstract}
ABSTIMACT
Mindset theory of action phases is based on the distinction between motivation and volition as proposed by the Rubicon model which claims that prior to crossing the Rubicon (i.e., making a goal decision) motivational principles apply whereas thereafter volitional principles set in. The latter are concerned with goal implementation, whereas the former relate to the choosing of goals. Mindset theory of action phases proposes that different cognitive procedures are activated when people tackle the task of choosing goals versus implementing them. The respective task demands determine the features that characterize the deliberative versus implemental mindset. These pertain to what type of information is preferably processed and how it is analyzed. Mindset research has produced findings that not only support the motivation versus volition distinction but also enlighten various debates and theories in social psychology (e.g., optimism versus realism debate, dual process theories, goal theory). Mindset theory of action phases has also spurred research on effective planning by pointing to implementation intentions (i.e., if-then plans). This research has had much applied impact. When it was linked up to research on strategies of motivationally smart goal setting (i.e., mental contrasting), it initiated the development of a time- and cost-effective behavior change intervention.
\end{abstract}

\section{INTRODUCTION}

During my graduate education in the late 1970s at the University of Texas at Austin, my mentor, Robert Wicklund, and I started to conceive of people's selves or identities as goals. We thought that people can very well set themselves goals to become a good parent, a brilliant scientist, or a great athlete. If one takes this perspective, the self of a person is no longer just something to understand (self-concept) and like (self-esteem) but something to be achieved (identity goal). We turned to the writings of Kurt Lewin (1926) and his students, whose tension system theory of goal pursuit, with its notion of substitution, was very helpful to developing our theory of symbolic self-completion (Gollwitzer and Kirchhof, 1998; Wicklund and Gollwitzer, 1982). The main proposition of self-completion theory is that once people have set themselves certain identity or selfdefining goals, they respond to failure experiences, shortcomings, or barriers not with retreat but instead with intensified efforts to reach the goal. These efforts, however, do not 
have to alleviate the problem at hand but may involve resorting to any substitute that indicates goal attainment (e.g., showing off relevant status symbols, engaging in identityrelevant activities, describing oneself as having the required personal attributes; for recent research on self-completion theory see Gollwitzer et al., 2009; Harmon-Jones et al., 2009; Ledgerwood et al., 2007).

In the early $1980 \mathrm{~s}$, Heinz. Heckhausen invited me to join the newly founded Max Planck Institute for Psychological Research at Munich to start a research unit called Motivation and Action. We quickly realized that we had a directly opposed conceptual view of motivation. Whereas Heinz Heckhausen's motivation was that of an expectancy-value theorist in the tradition of Atkinson (1957) and Heckhausen (1977) and was thus fueled by the perceived feasibility and desirability of a given action, my motivation was that of Lewin's (1926) tension system and was resting in the determination or commitment a person holds with respect to the action goal at hand. Apparently, in the research on self-completion (Wicklund and Gollwitzer, 1982) I had been studying issues of goal striving (i.e., thoughts and behavior directed toward existing goals), whereas Heinz Heckhausen in his work on achievement motivation (Heckhausen, 1977) had focused on issues of goal setting (i.e., what goals people find attractive and feasible, and thus choose for themselves).

\section{THE RUBICON MODEL OR ACTION PHASES}

To highlight this insight, we suggested making a distinction between motivation and volition. Following the conceptual terms used by Lewin (1926) and NarziB Ach (1935), we dubbed the goal-striving-related motivation with the term volition, and kept the term motivation for the goal-setting-related motivation. More importantly, in an attempt to integrate these two kinds of phenomena (i.e., motivation and volition) we developed the Rubicon model of action phases (Heckhausen, 1987; Heckhausen and Gollwitzer, 1987). This model suggests that the course of action can be segmented into four different, consecutive phases that differ in terms of the tasks that are to be solved by the individual given that s/he wants to execute a given course of action successfully. The first phase (predecision phase) is said to pose the task of setting preferences among wishes and desires by deliberating their desirability and feasibility. As people's motives and needs produce more wishes and desires than can possibly be realized, the individual is forced to choose among these desires and by doing so turn them into goals. Once goals are set (i.e., the Rubicon has been crossed), the individual faces the second task (preaction phase), which is getting started with goal-directed behaviors. This may be simple if the necessary goal-directed actions are well practiced and routine but complex if the individual is still undecided about where, when, and how to act. In such complex cases, the execution of goal-directed action has to be planned by deciding on when, where, and how to act. The third task (action phase) is bringing the initiated goal-directed action to a successful ending, and this is best achieved by determined and persistent pursuit of goal completion. Finally, in the fourth task (postaction phase), the individual needs to decide whether the desired goal has indeed been achieved or whether further striving is needed.

The Rubicon model of action phases postulates that a person's psychological functioning in each of these phases is governed by different principles. Classic theories of motivation (adhering to the restricted definition of motivation as determined by feasibility and desirability; Atkinson, 1957; Feather and Newton, 1982; Heckhausen, 1977) are said to be well suited to explicate the psychological processes associated with the predecision and postaction phases, whereas theories of volition (i.e., theories on the selfregulation of goal attainment; Lewin, 1926; 
Mischel, 1974; Mischel and Patterson, 1978) are most appropriate to explaining the psychological processes that characterize the preaction and action phase. In other words, the predecision and postaction phases are expected to encompass motivational phenomena and processes in the classic sense of the term, whereas in the phases in between volitional phenomena and processes are thought to occur.

This radical statement needed empirical support, and therefore Heckhausen and I conducted an early experiment aimed at demonstrating that individuals placed in the predecision phase evidence different cognitive functioning than do individuals in the preaction phase (Heckhausen and Gollwitzer, 1987, Study 2). Assuming that deliberation of the desirability and feasibility of wishes and desires (the task of the predecision phase) is cognitively more demanding than committing to a plan that specifies, when, where, and how one wants to perform goal-directed actions (the task of the preaction phase), we expected that deliberating individuals experienced a higher cognitive load than planning (i.e., preaction) individuals. We therefore interrupted experimental participants who were either in the middle of deliberating a choice between two different tests that presumably measured their creative potential or in the middle of planning how to perform the test they had just chosen and then asked them to take a short-term memory test (i,e., a noun span test that presented nouns irrelevant to the creativity tests at hand). We expected that deliberating participants, because of heightened cognitive load, would evidence a reduced noun span, compared with their span as measured at the beginning of the experiment. We also expected that deliberating participants would evidence a comparatively more reduced noun span than planning participants because laying down a plan on how to act was expected to take up less cognitive resources than deliberating the pros and cons of a goal decision.

To our surprise, the results were just opposite to what we had predicted (Heckhausen and Gollwitzer, 1987, Study 2). The deliberating participants showed an increase in their short-term memory capacity, compared with both their own prior span and the span of the planning participants. In an effort to reduce our confusion about these unexpected findings, I turned to Gerhard Strube, at the time a cognitive psychologist at the MaxPlanck-Institute for Psychological Research, and he pointed me to the classic concept of mindset as originally advanced at the turn of the century by the German psychologists Külpe (1904), Marbe (1915), Orth (1903), and Watt (1905), all members of the Würzburg school. These early cognitive psychologists had discovered that becoming intensively involved with performing a given task activates exactly those cognitive procedures that help task completion. The created mindset (i.e., the sum total of the activated cognitive procedures) is the cognitive orientation most conducive to successful task performance.

The mindset notion allows interpreting the observed noun span data as follows: deliberating between potential action goals activates cognitive procedures (the deliberative mindset) that facilitate the task of the predecision phase, which is to set preferences. As undecided individuals do not know yet in which direction their decisions will finally take them, a heightened receptiveness to all kinds of information (open-mindedness) seems appropriate and functional to task solution. Similarly, planning out the implementation of a chosen goal should activate cognitive procedures (the implemental mindset) that facilitate the task of the preaction phase (i.e., getting started on the chosen goal). As this requires a more focused and selective orientation to processing information, closed-mindedness rather than open-mindedness with respect to available information seems called for. This postulated difference in receptiveness between deliberating and planning individuals is expressed in the fact that the experimental participants in the Heckhausen and Gollwitzer (1987, Study 2) noun span study processed the presented information in the noun span task 
faster than planning participants (i.e., the deliberating participants demonstrated a broader noun span than the planning participants).

\section{MINOSET THEORY OF ACTION PHASES}

However, isn't all of this post hoc? This is exactly the type of worry that made me use the mindset notion as a hypothesisgenerating device for subsequent research and thus for developing a comprehensive mindset theory of action phases in my Habilitationsschrift (i.e., a second, more extensive doctoral thesis that in Germany is a prerequisite for attaining a tenured professorship; Gollwitzer, 1987). A summary of this thesis (Gollwitzer, 1990) can be found in a chapter in Motivation and Cognition edited by E. Tory Higgins and Richard M. Sorrentino (1990), and a more extensive version in a German book, Abwägen und Planen [Deliberating and Planning] (Gollwitzer, 1991). If one analyzes the unique demands of the task of choosing between wishes and desires in the predecision phase versus the typical demands of the task of getting started on a chosen goal in the preaction phase, it becomes possible to detect further cognitive features of the deliberative as compared to the implemental mindset that can then be tested in new experiments. The task of deliberating in the predecisional phase is to choose, from among various wishes and desires, those few that one wants to realize (Gollwitzer, 1990). The criteria for selection should be the feasibility and desirability of the wishes and desires at issue. The systematic analysis of the chances of realization as well as the desirability of realization requires that relevant information be preferentially encoded and retrieved. But such cognitive tuning to this information should not suffice, as feasibility-related information needs to be analyzed objectively (and not in a selfserving manner), and desirability-related information needs to be analyzed in an impartial manner (and not in a biased manner). Only if feasibility-related information is analyzed realistically, and the pros and cons are weighed impartially, can the individual turn those desires into binding goals that can potentially be realized and possess a genuine attractiveness. Moreover, deliberating requires a general open-mindedness (as was demonstrated in the Heckhausen and Gollwitzer [1987] study described above) with respect to any available information, as undecided individuals do not know yet in which direction their decision will finally take them.

Once a goal decision has been made, the task of planning is to promote the initiation of goal-directed behavior. This requires committing oneself to when, where, and how to get started. Accordingly, one needs to discover good opportunities and link them to appropriate goal-directed actions, thus creating plans for action. For this purpose, cognitive tuning toward implementation-related issues should be beneficial. Feasibilityrelated and desirability-related issues should no longer matter, and, if forced on the individual, they are avoided by distorting the relevant information in support of the goal decision made; the person sees the feasibility of the chosen goal in an overly optimistic way, and views the desirability of the chosen goal in a partial manner (i.e., pros exceed cons). Finally, processing all of the available information in an open-minded manner should be dysfunctional, as it might derail the individual from the chosen course of action. Accordingly, a reduced open-mindedness (closed-mindedness) favouring the selective processing of information in support of the chosen goal is to be expected.

Given these different features of the deliberative and implemental mindsets, one should not forget that the two different mindsets also possess many similar attributes. For instance, the mindset theory of action phases assumes that both deliberative and implemental mindsets become more pronounced as a person gets more involved with deliberating between potential goals and with planning chosen 
goals, respectively. Moreover, neither mindset should immediately vanish when the task activity that produced it is ended; instead, the mindset should show a moment of inertia. This implies that the cognitive orientations associated with the deliberative and implemental mindsets can be detected in their effects on performing temporally subsequent tasks of a different nature. These ideas regarding the similarity between the deliberative and implemental mindset have been used to develop a research program aimed at testing the proposed different cognitive features of the deliberative and implemental mindsets.

In this research, the following method of inducing the deliberative and implemental mindsets turned out to be most effective: experimental participants are asked either to extensively deliberate an unresolved personal problem to be named by the participants (who indicate problems such as, "Should I move to another city or not?", "Should I change my major?", "Should I buy a new car?", or "Should I get involved with somebody?") or to plan the implementation of a chosen goal indicated by the participants (projects such as, "I will move to another city," "I will change my major," etc., are named). These requests create a deliberative and an implemental mindset, respectively. To intensify these mindsets, deliberating participants are asked to list the short-term and long-term pros and cons of making and not making a decision, in order to get heavily involved with deliberating. Planning participants, on the other hand, are asked to list the five most important steps of implementing the chosen goal, and then to specify when, where, and how they intend to execute each step, all of which serves the purpose of creating an intensive involvement with planning. Thereafter, both the deliberating and the planning participants are asked to perform presumably unrelated tasks (usually presented by a different experimenter in a different situational context), which are designed to measure the very cognitive features hypothesized to differ between the deliberative and implemental mindsets.
This procedure of inducing the deliberative and implemental mindsets in one situational context and assessing their cognitive and behavioral consequences in a different setting, has been referred to as procedural priming or mindset priming (Bargh and Chartrand, 2000), as research participants commonly stay unaware of the mindset effects they evidence.

\section{Deliberative versus implemental mindsets and cognitive tuning}

The hypothesis that the deliberative mindset creates cognitive tuning toward information relevant to making goal decisions (information on feasibility and desirability), whereas the implemental mindset tunes a person's cognitions to implementation-related information (information on where, when, and how to act), was tested most critically by Gollwitzer et al. (1990). Participants were placed into either a deliberative or an implemental mindset by having them deliberate on unresolved personal problems or plan chosen goal projects, respectively (the standard procedure described above was used). In a presumably unrelated second part of the experiment, participants were presented with the first few lines of a number of novel fairy tales and were instructed to complete each tale. Even though participants were allowed to continue the stories in any way they liked, deliberating participants had the protagonists of the tales reflect on reasons for choosing or not choosing certain action goals to a greater degree than planning participants did. Thoughts about how to accomplish a chosen goal, however, were more frequently attributed to the protagonists by planning participants than by deliberating participants.

Focusing on the processing of mindsetcongruent information, Gollwitzer et al. (1990, Study 2) conducted an experiment in which participants had to recall the presented deliberative and implemental thoughts of others. Participants were placed into either a deliberative or an implemental mindset by 
having them reflect the choice of one of two tests (i.e., decide between two different creativity tests) or plan to perform a chosen test. While participants were involved in deliberating or planning, slides were presented that depicted different persons mulling over personal decisions. For example, a depicted elderly lady was thinking of the pros (i.e., "It would be good because ...") and cons (i.e., "It would be bad because ...") of having her grandchildren spend their summer vacation at her home. For each of these slides, next to the pros and cons of making a decision, potential plans of implementation were also presented. These specified how the person would get started with the particular goal-directed actions (i.e., "If I decide to do it, then I will first ... and then ...!"; "If I decide to do it, then I won't ... before ...."'). A cued-recall test of this information was given following a distractor task; it provided participants with the pictures of the persons they had viewed and the stems of the sentences (as above) describing their thoughts. The deliberating participants, who had to view the slides and to recall the information depicted on the slides prior to making a decision about the two types of creativity tests, recalled pros and cons better than they recalled information on the when, where, and how of implementation. The recall performance of the planning participants, who had received and recalled the information after a decision on the creativity tests had been made, showed the reverse pattern.

All of these findings corroborate the cognitive-tuning hypothesis. But how do these differential recall performances observed in the last study (Gollwitzer et al., 1990, Study 2) come about? If one assumes that individuals' retrieval attempts necessitate constructing descriptions of what they are trying to retrieve (Norman and Bobrow, 1979), it seems possible that mindsets provide perspectives (Bobrow and Winograd, 1977) that allow the easy construction of specific descriptions. The deliberative mindset for instance should favour descriptions phrased in terms of pros and cons, benefits and costs, and so forth. In other words, the deliberative mindset supports the ready construction of descriptions that specify desirability-related information, whereas the implemental mindset supports the construction of descriptions that specify implementation-related information. As Norman and Bobrow (1979) point out, quick construction of specific descriptions at the time of retrieval facilitate further successful retrieval. Norman and Bobrow also assume that whenever the description of the information sought matches the elaboration of the information at the time of encoding, recall performance is particularly enhanced. It seems possible, then, that deliberative and implemental mindsets favor congruent recall through both congruent elaboration at the time of encoding and ready construction of congruent descriptions at the time of retrieval.

\section{Deliberative versus implemental mindsets and biased inferences}

Deliberative and implemental mindsets are also postulated to differentially affect the way in which feasibility-related and desirability-related information is handled. In a deliberative mindset, information related to desirability should be analyzed impartially; in an implemental mindset, an analysis partial to the chosen goal is expected. Also, feasibility-related information is expected to be analyzed rather accurately in a deliberative mindset, whereas optimistic inferences that overestimate the actual feasibility of the chosen goal are expected in an implemental mindset.

\section{Desirability-related information}

With respect to testing the postulated impartial versus partial analysis of desirabilityrelated information, a first study (reported by Taylor and Gollwitzer, 1995, Study 3) was conducted by asking participants to name either potential goals or chosen goals and 
subsequently attempt to achieve clarity on the question of whether they should make an affirmative decision or had made the correct decision, respectively. Whereas the predecisional participants reported on positive and negative consequences with the same frequency, postdecisional participants failed to do so. The latter reported about five times more thoughts about pros than about cons, indicating a strong partiality in favor of the chosen goal in postdecisional participants.

Evidence for differences between the deliberative and implemental mindset in processing pros and cons is also provided by Harmon-Jones and Harmon-Jones (2002, Study 2). They tested the effects of mindsets on the postdecisional spreading of alternatives, a classic cognitive dissonance paradigm (Brehm and Cohen, 1962). Using this paradigm, dissonance researchers have found that after making a choice between two options, the chosen option becomes evaluated more positively whereas the nonchosen option becomes evaluated more negatively. Harmon-Jones and Harmon-Jones found that the implemental mindset increased postdecisional spreading of alternatives, whereas the deliberative mindset reduced it.

There is an important set of studies by Gagné and Lydon (2001a) suggesting that deliberation only then leads to an impartial analysis of pros and cons when deliberation is linked to the predecisional action phase. Deliberation over goal decisions that have already been made can initiate defensive processing of information that leads to even greater biasing. In one study, they asked participants involved in romantic relationships to deliberate a relationship or a nonrelationship goal decision. They found that when asked to rate how their partner compared with the average, those individuals asked to deliberate over a relationship goal decision gave much higher ratings than those who were asked to deliberate over a nonrelationship goal decision. Of interest, these ratings were also higher than those of implemental participants who had been planning the implementation of a relationship goal.
Gagné and Lydon (2001a) argue that the deliberation of a relationship goal may have been perceived as threatening, resulting in greater enhancement of the partner's attributes. In a second study, they measured the commitment participants had to their relationship and found that high-commitment but not low-commitment participants defended against the threat of a deliberative mindset by increasing their positive views of their partner. This pattern of findings indeed supports the assumption that deliberation may have threatened the participants' perceived ability to attain the goal of maintaining the relationship. In response, these individuals reasserted their commitment to the relationship by boosting the ratings of their partner.

\section{Feasibility-related information}

The hypothesized accurate analysis of feasibility-related information in the deliberative mindset, and the expected overly optimistic assessment in the implemental mindset, were observed in experiments by Gollwitzer and Kinney (1989) using the contingencylearning task designed by Alloy and Abramson (1979). In this task, participants are asked to determine to what degree they can influence the onset of a target light (outcome) by choosing to press or not to press a button (alternative actions). Participants commonly go through a series of trials (at least 40); the start of each trial is indicated by a warning light. By observing whether or not the target light comes on after they have pressed or not pressed the button, participants estimate how much control they have over the target light onset. The experimenter varies the actual control by manipulating the frequency of the target light onset associated with each of the two action alternatives (pressing or not pressing). The smaller the difference between these two frequencies, the less objective control participants have over the target light onset.

Nondepressed individuals commonly claim to possess control over target light onset that is noncontingent on their actions, 
whenever the target light onset occurs frequently (e.g., in the "75/75" problem, where the target light comes on in 75 percent of pressing and 75 percent of nonpressing responses; see Alloy and Abramson, 1979). Gollwitzer and Kinney (1989. Study 2) asked deliberating, planning, and control participants to work on a contingency problem that presented frequent and noncontingent target light onset (i.e., the 75/75 problem). Participants were given the instruction to discover how to produce the target light onset. A set of 40 trials was offered, and participants were then asked to judge how much control they could exert over the target light onset.

Deliberating participants showed the most accurate judgment of control; their judgments of control were lower than those of either the control group or the planning group. The planning participants' judgments of control tended to be even higher than those of the control participants. The mindsets were created via the standard procedure described above. A mindset interpretation of these findings is supported by the additional observation that deliberating participants' judgments of control correlated negatively with the personal importance of the unresolved personal problems these participants were mulling over. Apparently, the more involved participants were in deliberating, the more realistic their subsequent judgments of control. A parallel finding was observed for planning participants, whose judgments of control were positively related to the participants' anticipated frustration in case they should fail to implement their chosen goals.

When Shelly Taylor asked me to collaborate on studies testing whether deliberative and implemental mindsets might even differentially affect the perceived controllability of events in everyday life, I was happy to assent. We observed (Taylor and Gollwitzer, 1995, Study 1) that the deliberative and implemental mindset indeed manage to affect people's judgments of the controllability of everyday risks (e.g., the risks involved being in an automobile accident, becoming divorced, becoming depressed, developing a drinking problem, and being mugged). Participants were college students who had to judge these risks for themselves and for the average college student. Mindsets were induced via the standard procedure just before participants had to judge the named risks. Even though all participants perceived themselves as less vulnerable to these risks than the average college student, deliberating participants did this to a lesser degree than planning participants. This more pronounced illusion of invulnerability in the implemental mindset than in the deliberative mindset held no matter whether the critical events to be considered were of a more or less controllable (e.g., developing an addiction to prescription drugs, having a drinking problem) versus uncontrollable kind (e.g., developing diabetes, losing a partner to an early death). For both types of events, planning participants reported a higher invulnerability as compared to the average college student than deliberating participants did. The fact that deliberative and implemental mindsets even managed to modify the perceived vulnerability of rather uncontrollable events attests again to their enormous influence on the analysis of feasibility-related information.

We reasoned that assessing the feasibility of potential goals in the predecisional action phase not only requires that people accurately assess whether their actions could effectively control desired outcomes, they also need to know whether they are in the position to perform these instrumental actions. To answer this question, they have to assess correctly whether they possess the relevant aptitudes and skills. This implies that people in a deliberative mindset should show a relatively accurate evaluation of their personal attributes. Accordingly, we (Taylor and Gollwitzer, 1995, Study 2) also asked deliberating and planning participants to rate themselves on 21 qualities and skills (e.g., cheerfulness, athletic ability, writing ability, popularity, artistic ability) in comparison with the average college student of the same 
age and gender. Even though all participants perceived themselves as more capable than the average college student, planning participants did so to a higher degree than deliberating participants. More recent research by Bayer and Gollwitzer (2005) suggests, however, that deliberative and implemental mindset effects on perceived ability may be moderated by people's relevant original low versus high self-views. The deliberative mindset helped in particular people with originally high self-views to arrive at modest ability appraisals (that foster the setting of realistic goals); and it was again in particular people with originally high self-views that were helped by the implemental mindset to arrive at optimistic ability appraisal (that foster the attainment of chosen goals).

A study by Puca (2001) also speaks to the biased analysis of feasibility-related information in the implemental as compared to the deliberative mindset. She studied realism versus optimism in terms of choosing test materials of different difficulty (Study 1) and predicting their own future task performance (Study 2). Deliberative participants preferred tasks of medium difficulty, whereas implemental participants opted for the too difficult tasks; also, implemental mindset participants overestimated their probability of success more than deliberative participants. Moreover, deliberative participants referred more than implemental participants to their past performance when selecting levels of difficulty or predicting future performance. Finally, when Gagné and Lydon (2001b) moved this biased inferences research to the real world by studying the issue of relationship predictions they found that individuals with a deliberative mindset were more accurate in their forecasts of survival of their romantic relationships than individuals with an implemental mindset. This effect was even more pronounced for long-term than for short-term relationship survival. Of most interest, participants with a deliberative mindset did not achieve this heightened accuracy by simply taking a pessimistic attitude.

\section{Deliberative versus implementeal mindsets and open mindedness}

Beyond differences in cognitive tuning and biased inferences, deliberative and implemental mindsets should also differ in openness to information. Task analysis of the demands of making a goal decision suggests that deliberative mindsets should be associated with enhanced receptivity to all sources and types of information. To make good decisions, one should be open to any available information that might potentially inform one's decision-making. One should be careful not to dismiss information prematurely as it may ultimately be useful or helpful in making good goal decisions. Implemental mindsets, in contrast, should be associated with more selective information processing. Once a goal is set, successful goal implementation requires more particular filtering of information, selectively processing goalrelevant stimuli while ignoring goal-irrelevant stimuli (e.g., Gollwitzer, 1990; Kuhl, 1984). For these reasons, the deliberative mindset should be associated with greater openness to information incidental to one's goals.

The early study by Heckhausen and Gollwitzer (1987, Study 2) reported above bears some relevance to this hypothesis. Participants were interrupted either while they were deliberating a choice between two different creativity tests (deliberative mindset), or just after having chosen one of them (implemental mindset), and verbally presented with lists of five to seven onesyllable nouns (e.g., house, art, and tree). Immediately after each list had been presented, participants had to recall the words in order. Participants' performance in this task was used to compute their working memory span (i.e., noun span), and results indicated that deliberative mindset participants evidenced a broader span (about half a word more) than implemental mindset participants.

The superior noun span by deliberative as compared with implemental mindset participants, however, only suggests that 
deliberative mindset participants are more capable of storing information (i.e., they have a broader working memory span). Although broadened working memory suggests an enhanced capacity to process information, it does not directly address the hypothesis that deliberative mindsets, as compared with implemental mindsets, are associated with heightened processing of information that is incidental to one's goals. The information in the word lists used in the Heckhausen and Gollwitzer (1987) study cannot be considered incidental. Participants were explicitly asked to correctly reproduce as many words as possible of each presented word list. Moreover, broader working memory span by itself does not necessarily lead to more or less selective processing of incidental information.

Accordingly, Fujita et al. (2007) attempted a more critical test of the hypothesis that there are differences between the deliberative and implemental mindset in the selective processing of incidental information. In three experiments, participants in deliberative and implemental mindsets performed a primary task (d2-concentration test; Brickenkamp, 1981) while randomly presented incidental, unavoidable words. A subsequent unexpected recognition memory test assessed selective processing of these incidental words. In Study 1, they observed that participants in a deliberative mindset took less time than those in an implemental mindset to recognize whether or not they had previously been exposed to incidental words presented in a concentration task. In Studies 2 and 3, participants in a deliberative mindset had higher recognition accuracy of these words as compared with those in an implemental mindset. The results from all three studies indicate that deliberative individuals more easily accessed memory traces of information incidental to the ongoing task than implemental individuals. This occurred even when the mindsets induced were unrelated to the performance task that measured the cognitive differences (Studies 2 and 3). This "carryover" effect of mindsets suggests that whereas the implemental mindset is more selective, the deliberative mindset is more open-minded to incidental information available in one's immediate environment Study 3 also allowed clarifying whether the effect of mindset on selective information processing was due to enhanced openmindedness in the deliberative mindset, enhanced closed-mindedness in the implemental mindset, or both. Results from this study suggested that the change in selective processing as a function of mindset is attributable to less selective filtering of incidental information in the deliberative mindset, as opposed to greater selective filtering in the implemental mindset.

Finally, the three studies taken together indicate that changes in selective processing as a function of mindset occur preconsciously. Preconscious cognitive processes are those that are initiated and do operate outside of conscious intent (Bargh, 1994). Researchers have argued that reactions to stimuli that require a response within $300 \mathrm{~ms}$ are not consciously controlled (e.g., Bargh and Chartrand, 2000; Greenwald and Banaji, 1995). Participants in all three studies were presented with incidental stimuli for only $300 \mathrm{~ms}$ prior to the primary performance task materials. Apparently, the act of deliberating a goal decision produces dramatic changes in the cognitive processing of information even when individuals do not intend such changes.

\section{Deliberative versus implemenễal mindsers and behavior}

Gollwitzer and Bayer (1999) pointed out that mindsets have been analyzed primarily in terms of their cognitive features, whereby the effects of these features on the control of behavior were ignored. As an exception, they reported a study by Pösl (1994), who found that participants in the implemental mindset were faster to initiate goal-directed behavior than those in the deliberative mindset. This was particularly true when participants experienced a behavioral conflict (i.e., whether 
they had a choice to perform Behavior A or $B$, or only one of these), suggesting that the implemental mindset's closed mindedness allows participants to stay on track even in the case of behavioral conflict.

There is also evidence that the implemental mindset generates greater persistence in goal-directed behavior. Brandstätter and Frank (2002) found that participants in the implemental mindset persisted longer at an unsolvable puzzle task (Study 1) and at a self-paced computer task (Study 2). Similar to the findings of Pösl (1994), the impact of the implemental mindset on persistence was present in particular in situations of behavioral conflict. When both the perceived feasibility and desirability of the tasks were either uniformly high or low, persistence on the persistence tasks did not differ by mindset. However, when the perceived feasibility and desirability of the tasks were in opposite directions (i.e., one was high whereas the other was low) the implemental mindset participants persisted longer than did the deliberative mindset participants. Interestingly, the persistence in the implemental mindset was not executed insensitively or in a blind fashion. Brandstätter and Frank (2002, Study 3) obtained evidence that when a task is perceived as impossible or when persistence is not beneficial, individuals in the implemental mindset disengage much more quickly than individuals in the deliberative mindset.

Finally, Armor and Taylor (2003) report that an implemental mindset facilitates task performance (i.e., a scavenger hunt to be performed on campus) as compared with a deliberative mindset, and that this effect is mediated by the cognitive features of the implemental mindset (i.e., enhanced selfefficacy, optimistic outcome expectations, perceiving the task as easy). Such a study had been missing so far. Note that the Gollwitzer and Kinney (1989) study predicted cognitive changes (i.e., strong illusions of control) as a consequence of the implemental as compared with the deliberative mindset, because such illusions should benefit acting on the goal.
However, this inference had not been tested within one and the same study as was done by Armor and Taylor.

Recent research by Henderson et al. (2008) suggests that the beneficial effects of the implemental mindset on task performance might also be mediated by changes in respective attitude strength. The unambiguous, evaluative polarized or one-sided assessment of information in support of the chosen goal in the implemental mindset should foster the strength of the attitude toward the goal. Given the carryover properties of mindsets, Henderson et al. hypothesized that as people adopt an implemental mindset, they should experience an increase in attitude strength toward objects even if these are unrelated to their current goal pursuit. In a series of experiments they found support for this hypothesis. They observed that implemental mindset participants more than deliberative mindset participants adopt an extreme position towards an issue that is irrelevant to their goal concern. Moreover, implemental mindset participants evidenced lower levels of ambivalence toward a variety of unrelated objects than deliberative and neutral mindset participants. Implemental mindset participants were also characterized by more accessible evaluations of unrelated objects than deliberative and neutral mindset participants. And, importantly, implemental mindset participants showed a greater correspondence between their attitude and behavior than neutral mindset participants.

Finally, in order to investigate the process that is hypothesized to underlie the effects of an implemental mindset on attitude strength (i.e., one-sided focus on pros), Henderson et al. had implemental mindset participants either focus on the pros only or on both the pros and cons behind their decision. Critically, it was only the evaluative one-sided analysis of information that fostered attitude strength. As the authors had taken two groups who made a decision on how to act and only varied their evaluative focus (i.e., one group engaged in a one-sided evaluation of their 
decision, whereas the other group engaged in a two-sided evaluation of their decision), the act of deciding itself does not seem to be sufficient to increase attitude strength. Otherwise, those individuals who made a decision on how to act and who analyzed both sides of their decision would have evidenced the same level of attitude strength as those who analyzed only one side of their decision.

\section{Summary}

Under the assumption that the course of goal pursuit presents itself to the individual as a series of consecutive tasks that need to be solved in order to promote goal attainment, the concept of mindset has been introduced. Mindset theory of action phases argues that becoming involved in these tasks leads to characteristic cognitive orientations (mindsets) that are beneficial for solving these tasks effectively, and the features of the cognitive orientations associated with the tasks of choosing between potential action goals (the deliberative mindset) and preparing the implementation of chosen goals (the implemental mindset) are spelled out. Various experiments tested the postulated characteristics of the deliberative and implemental mindsets. This research shows that the deliberative mindset is characterized by cognitive tuning toward desirabilityrelated and feasibility-related thoughts and information, by an accurate analysis of feasibility-related information and an impartial analysis of desirability-related information, and, finally, by a heightened general receptivity to available information. The implemental mindset, on the other hand, is characterized by cognitive tuning toward implemental thoughts and information, by an overly optimistic analysis of feasibility-related information and a partial analysis of desirability-related information, and, finally, by a comparatively reduced receptivity (closed-mindedness) to available information.

\section{HWPLICATHONS POF OTHER THEORIES AND CONCEPTUAL DEBATES IN SOCHALSYCHOLOGY}

Mindset theory of action phases has received much attention in other theories and conceptual debates in social psychology. These pertain to the optimism versus realism debate and to dual process theories. How the mindset theory of action phases can help to clarify issues in these areas of research will be discussed next.

\section{Op:nimism versus realism}

The results of mindset research on the processing of feasibility-related information pertain to the illusionary optimism versus realism controversy triggered by Taylor and Brown's (1988) article on positive illusions. Taylor and Brown proposed that mentally healthy people are not characterized by accurate assessments of their personal qualities, realistic estimates of personal control, and a realistic outlook on the future; instead, they maintain overly positive, self-aggrandizing perspectives of the self, the world, and the future. More specifically, mentally healthy people are said to be characterized by unrealistically positive self-perceptions, an illusion of a high degree of personal control, and unrealistic optimism about the future. Instead of being maladaptive, these positively distorted perceptions foster the criteria normally associated with mental health: positive regard, the ability to care for and about other people, and the ability to manage stress effectively (Taylor and Brown, 1988). Despite empirical support for the model (Taylor and Armor, 1996; Taylor et al,, 2000), this portrait of the healthy person raises a disturbing question: if healthy people's perceptions are marked by positive bias, how do they effectively identify and make use of negative feedback they may encounter? If people are capable of explaining away, compartmentalizing, or otherwise dismissing or minimizing negative feedback, as Taylor and Brown 
(1988) suggested, these self-serving illusions that bolster self-esteem and produce a positive mood in the short run may ultimately set people up for long-term disappointment and failure as they fail to incorporate negative feedback into their goal setting and planning (Colvin and Block, 1994; Weinstein, 1984).

The mindset research on illusion of control offers the following insights to the debate about positive illusions versus realism. First, neither realism nor positive illusions seem adaptive in general to a person's psychological functioning. Realistic thinking seems functional when it comes to making goal decisions, whereas positive illusions seem functional when the chosen goals are to be implemented. Second, people can easily open the window to realism provided by the deliberative mindset. People do not have to go through the effortful mental exercises we have induced in our experiments to create a deliberative mindset; simply trying to achieve clarity in regard to an unresolved personal problem will trigger an intensive deliberation of pros and cons (Taylor and Gollwitzer, 1995, Study 3). Third, postdecisional individuals who plan the implementation of a chosen goal seem to be protected from an accurate analysis of feasibility-related information and thus can benefit from illusionary optimism that makes them strive harder to reach their goals, especially in the face of hindrances and barriers. It appears, then, that the individual's cognitive apparatus readily adjusts to the various demands of the control of action: choosing between action goals leads to realism, and implementing chosen goals leads to positive illusions.

\section{Dual process theories}

The ideas and research originating within the framework of the notion of deliberative and implemental mindsets seem to constitute a dual process theory in the realm of goal pursuit. The approach taken is to juxtapose a cognitive orientation that is functional to choosing goals with a cognitive orientation that is functional to the implementation of chosen goals. In other words, the ideal information-processing styles for solving two different tasks that serve one end (i.e., the effective control of action) are analyzed in contrast to each other. This is different from those dual process models that compare two different styles of information processing in the service of one and the same task, such as perceiving another person (Bargh, 1984; Brewer, 1988; Fiske and Neuberg, 1990), making attributions (Gilbert, 1989; Gilbert and Malone, 1995), or forming attitudes (Chaiken et al., 1989; Fazio, 1990). The approach taken in those models is to analyze how the two forms of information processing delineated differ in meeting the task at hand as is also true for those dual process lines of research that explicitly adopt the mindset notion for conceptual and methodological reasons, such as research on the counterfactual mindset (e.g., Galinsky and Moskowitz, 2000; Wong et al., 2009) and near versus distal mental construal (e.g., Liberman and Trope, 2008; Freitas et al., 2004). Counterfactual mindset research induces a counterfactual mindset by having participants read one and the same behavioral episode experienced by another person that is known to trigger counterfactual musings ("If only he had done ...," or "What if he had done ..."), and then checks whether reading as compared to not reading this episode improves performance in subsequent classic problem solving, creativity, or negotiation tasks. Mental construal research, on the other hand, studies how inducing psychologically distant versus near construals of certain events affects the perception, categorization, judgmental inferences, evaluations, and behaviors with respect to these events as well as related events. Note that the attempted gain in knowledge of these two approaches refers to how a given cognitive orientation (counterfactual, near versus distal mental construal) affects respective cognitive, affective, and behavioral performances. With respect to the mindset theory of action phases, 
however, the attempted gain of knowledge refers to the typical characteristics of deliberating versus planning in terms of the underlying cognitive procedures.

However, there are some similarities between the deliberative versus implemental mindset distinction and those dual process notions that are construed as stage theories (e.g., Gilbert and Malone, 1995). People in everyday life should experience deliberative mindsets prior to implemental mindsets as people mostly prefer to make plans on how to achieve a goal only after they have made a binding goal choice. In this temporal sense therefore the deliberative versus implemental mindset model qualifies as a stage model. This is not true, however, with respect to the quality of cognitive processes associated with the two mindsets. For instance, in the two-step model of the attribution process - a stage model suggested by Gilbert (1989; Gilbert and Malone, 1995) - the first step is simple and automatic (i.e., a quick personal attribution), whereas the second step requires attention, thought, and effort (i.e., adjusting that inference to account for situational influences). The notion of deliberative versus implemental mindsets, on the other hand, does not assume that the deliberative mindset is associated with more rudimentary cognitive processes than the implemental mindset (or vice versa). In both the deliberative mindset and the implemental mindset, highly complex cognitive procedures are activated that determine the individual's cognitive and behavioral functioning. Moreover, in both deliberative and implemental mindsets these procedures can, but do not need to, reach consciousness to unfold their effects, and their effects can, but do not have to, be detected by the individual (e.g., the illusion of control in the implemental mindset).

Also, mindset theory sees the deliberative and implemental mindsets as distinct and independent of each other. Whereas it is assumed in some dual process theories (e.g., Chaiken et al., 1989) that the postulated modes of information processing can operate at the same time, the deliberative and implemental mindsets are assumed to preclude each other. This is because the strength with which the cognitive procedures associated with the deliberative mindset are activated is positively related to the degree of involvement with the task of choosing between potential goals, whereas the strength with which the cognitive procedures associated with the implemental mindset are activated is positively related to the degree of involvement with the task of planning the implementation of a chosen goal. Because a person cannot become intensely involved in both of these tasks at one and the same time but only successively, pronounced deliberative and implemental mindsets cannot coexist. They also do not affect each other in the sense that a preceding strong deliberative mindset makes for a strong succeeding implemental mindset; it all depends on how intensely people become involved with solving the task of choosing between potential goals and with planning the implementation of a chosen goal, respectively.

\section{Summary}

The deliberative versus implemental mindset distinction had an impact on various theoretical discussions in social psychology. First, with respect to the realism versus optimism discussion, it made clear that people are capable of flexibly adopting the type of orientation that is demanded by the task at hand. When decisions between goals are to be made (e.g., whether to go to college at home or abroad), getting involved with reflections on which goal to choose spurs realism that in turn allows making the more appropriate (feasible) choice. And if a chosen goal (e.g., studying abroad) is to be implemented, getting involved with planning out the course of goal realization spurs optimism that promotes the necessary persistence for goal attainment. Second, with respect to classic dual process theories, the mindset theory of action phases points out that modes of information processing may not only be studied in 
terms of what determines taking one or the other mode (e.g., heuristic versus systematic information processing is found to be affected by time pressure, likeability of the source, strong versus weak arguments), and what effects taking one or the other mode has on grasping the information at hand (e.g., leads to more or less respective attitude change). Mindset theory of action phases suggests that the mere involvement with one or the other type of reasoning task (deliberating the choice of potential goals versus planning the implementation of a chosen goal) already activates different task-facilitating cognitive procedures that affect the processing of both task-relevant and task-irrelevant information in a unique way.

\section{THE APPLIED IMEACT OF THE MINDSET THEORY OF ACIION PHASES}

Mindset theory of action phases had set aside the question of what makes for good planning of goal implementation. So when I was invited to create a research unit on "Intention and Action" at the Max Planck Institute for Psychological Research at Munich in 1989, this question became our central concern and has stayed with me ever since. As we had induced the implemental mindset by asking research participants to list a series of steps toward goal attainment and then specify for each individual step exactly when, where, and how one wants to realize it, we wondered whether people could facilitate goal striving by planning out goal-directed action in this fashion. We referred to this type of planning as forming implementation intentions (Gollwitzer, 1993, 1999). Whereas goals (or goal intentions) merely specify desired end states ("I want to achieve goal X!"), implementation intentions in the format of "If situation $Y$ arises, then $I$ will initiate behavior Z!" additionally specify when, where, and how a person intends to strive for the goal. Implementation intentions thus delegate control over the initiation of the intended goal-directed behavior to a specified situational cue by creating a strong mental link between this cue and a goaldirected response. For example, a person who has chosen the goal to eat more healthily can form the implementation intention, "When I'm at my favorite restaurant and the waiter asks me for my order, then I'll request a vegetarian meal!" The mental links created by implementation intentions were assumed (Gollwitzer, 1999) to facilitate goal attainment on the basis of psychological processes that relate to both the anticipated situation (i.e., enhanced activation of the mental representation of the situation specified in the ifpart of the plan) and the intended behavior (i.e., automatic initiation of the response specified in the then-part of the plan once the critical situation is encountered).

I was fortunate to get to know Paschal Sheeran in the mid 1990s. His students and colleagues in England as well as mine in Germany set out to test the claimed positive effects of implementation intentions on goal attainment as well as the assumed underlying processes. Because forming an implementation intention implies the selection of a critical future situation, the mental representation of this situation becomes highly activated and hence more accessible. This heightened accessibility of the "if" part of the plan has been observed in numerous studies; it helps people to easily recall the specified situation and it leads to swift allocation of attention when the situation arises. Various studies also observed that the initiation of the goal-directed response specified in the then-component of an implementation intention exhibits features of automaticity; if-then planners are found to act quickly in the face of the critical situation, they deal effectively with cognitive demands, and do not need to consciously intend to act in the critical moment.

A meta-analysis involving over 8,000 participants in 94 independent studies revealed a medium-to-large effect size of implementation intentions on goal achievement (Gollwitzer and Sheeran, 2006). 
Importantly, implementation intentions were found to benefit goal-directed responses no matter whether these were cognitive, emotional, or behavioral in nature, and this held true in all kinds of goal domains (e.g., consumer, envirommental, antiracist, prosocial, academic, and health). Apparently, implementation intentions help people to better cope with the major problems of goal striving: getting started, staying on track, calling a halt to a futile goal striving, and not overextending oneself. Importantly, implementation intentions still show their beneficial effects when the going gets tough (Gollwitzer et al., 2010; Gollwitzer \& Oettingen, 2011); that is, when goal striving is limited by conditions that are very resistant to change by self-regulatory strategies (e.g., a low level of competence, a fierce competitor; or strong competing habitual responses).

A recent fMRI study conducted by Gilbert et al. (2009) provides an answer to the puzzling power of implementation intentions. Brain activity in the lateral area 10 was observed to move toward the medial area 10 when participants switched from performing an executive-function task by the guidance of a goal intention to performing the very same type of task by the guidance of an implementation intention. On the basis of an extensive meta-analysis on various executive-function tasks it is known that lateral and medial area 10 are implicated in top-down and bottom-up action control, respectively (Burgess et al., 2005). Apparently, implementation intentions induce a switch in action control from top-down to bottom-up control of action. This explains why even habitual responses can be broken by implementation intentions, and why special populations that are known to suffer from ineffective conscious control of their thoughts, feelings, and actions are also found to benefit from forming implementation intentions (e.g., heroin addicts during withdrawal, schizophrenic patients, children with attention deficit hyperactivity disorder [ADHD]).

But will the discovery of an effective selfregulation strategy of goal striving and the in-depth analysis of how it works make people use it to solve personal, interpersonal, and even societal problems? Simply disseminating the good news of the existence of a powerful strategy for goal implementation may not suffice. It needs the second step of developing an intervention that facilitates the acquisition of this strategy so that people can use it on their own in everyday life. In other words, one needs to develop an intervention that effectively teaches the forming of implementation intentions as a meta-cognitive strategy.

To come up with such an effective intervention, Gabriele Oettingen and I first considered all of the studies that had analyzed potential moderators of implementation effects (see Gollwitzer and Sheeran, 2006). Importantly, implementation intentions only then unfold their beneficial effects if strong goal commitments are in place. Moreover, implementation intention effects seem to be stronger when people put exactly those cues in the if-part of an implementation intention which they personally consider to be most critical (Adriaanse et al., 2009). Accordingly, we looked for a procedure that established these prerequisites, and we found it in mental contrasting as this self-regulation strategy is also known to motivate if-then planning.

What is mental contrasting and how does it work? When people mentally contrast (Oettingen et al., 2001), they first imagine a desired future (e.g., to improve one's health behavior), and then reflect on the present reality that stands in the way of reaching this desired future (e.g., feeling the urge to give in to a temptation). Thereby, mental contrasting turns desired futures that are perceived as feasible into strong goal commitments. The beneficial effects of mental contrasting evince in various domains (achievement, interpersonal, and health), for cognitive (e.g., making plans), affective (e.g., feelings of anticipated disappointment in case of failure), motivational (e.g., feelings of energization, systolic blood pressure), and behavioral indicators of goal commitment (e.g., invested effort and 
actual achievement such as obtained course grades), directly after or weeks later (summary by Oettingen and Stephens, 2009). Mental contrasting facilitates strong goal commitments by changing implicit cognition. The increased strength of association between future and reality induced by mental contrasting has been found to mediate the cognitive, emotional, and behavioral indicators of strong goal commitment, measured by self-report and other-rated performance (Kappes and Oettingen, 2011).

We therefore integrated the forming of implementation intentions with mental contrasting into one self-regulation strategy called Mental Contrasting with Implementation Intentions (MCII; Oettingen and Gollwitzer, 2010). When taught as a meta-cognitive strategy that is then applied by participants in everyday life, it supports behavior change more than mental contrasting and implementation intentions used in isolation; moreover, MCII effects hold for various life domains (academic achievement, interpersonal relations, romantic satisfaction, and health, eating and regular exercise), and over time periods of up to two years (Adriaanse et al., 2010; Christiansen et al., 2010; Stadler et al., 2009, 2010). When engaging in MCII, participants first go through a mental contrasting exercise to create strong goal commitment and to identify the obstacles that truly stand in the way of goal attainment. Implementation intentions (if-then plans) are then formed to help translate the goal commitment into instrumental behavior by putting the obstacles identified in mental contrasting as critical cues in the if-part of the plan and linking it to an instrumental coping response specified in the then-part.

\section{CONCLUSION}

There are times when people need to make decisions, and there are times when the decisions made have to be implemented.
From the perspective of effective action control in everyday life, then, it seems helpful to activate the respective cognitive procedures that facilitate goal setting and goal implementation when making decisions versus acting on them is at issue. In other words, people should allow for and become involved in deliberative or implemental mindsets, depending on whether a goal decision or the implementation of a chosen goal is called for.

Moreover, there exist powerful strategies of pre- and postdecisional reasoning that are more effective than others. Accordingly, interventions geared at helping people to maximize their goal setting and goal striving should not merely confront people with the tasks of committing to goals and implementing the chosen goals. Rather, they should go one step further and equip people with those goal setting (e.g., mental contrasting) and goal implementation strategies (e.g., forming implementation intentions) that are known to be most effective in promoting appropriate goal commitments and successful goal attainment, respectively. Future research might explore how such strategies are taught best in time- and cost-effective behavior change interventions.

\section{REFEMENCES}

Ach, N. (1935) Analyse des Willens (The analysis of willing). In E. Abderhalden (ed.), Handbuch der biologischen Arbeitsmethoden, Vol. 6. Berlin: Urban u. Schwarzenberg.

Adriaanse, M.A., de Ridder, D.T.D. and de Wit, J.B.F. (2009) Finding the critical cue: Implementation intentions to change one's diet work best when tailored to personally relevant reasons for unhealthy eating. Personality and Social Psychology Bulletin. $35,60-71$.

Adriaanse, M.A., Oettingen, G., Gollwitzer, P.M., Hennes, E.P., de Ridder, D.T.D. and de Wit, J.B.F. (2010) When planning is not enough: Fighting unhealthy snacking habits by Mental Contrasting with Implementation Intentions (MCII). European Joumal of Social Psychology, 40, 1277-1293. 
Alloy, L.B. and Abramson, L.Y. (1979) Judgement of contingency in depressed and nondepressed students: Sadder but wiser? Journal of Experimental Psychology: General, 108, 449-485.

Armor, D.A. and Taylor, S.E. (2003) The effects of mindset on behavior: Self-regulation in deliberative and implemental frames of mind. Personality and Social Psychology Bulletin, 29, 86-95.

Atkinson, J.W. (1957) Motivational determinants of risk-taking behavior. Psychological Review, 64, 359-372.

Bargh, J.A. (1984) Automatic and conscious processing of social information. In R.S. Wyer, Jr. and T.K. Srull (eds), Handbook of Social Cognition, 3, 1-43. Hillsdale, N]: Erlbaum.

Bargh, J.A. (1994) The Four Horsemen of automaticity: Awareness, efficiency, intention, and control in social cognition. In R.S. Wyer Jr, and T.K. Srull (eds), Handbook of Social Cognition, 2nd Edition, pp. 1-40. Hillsdale, NJ: Erlbaum.

Bargh, J.A. and Chartrand, T.L. (2000) A practical guide to priming and automaticity research. In $\mathrm{H}$. Reis and C. Judd (eds), Handbook of Research Methods in Social Psychology, pp. 253-285. New York: Cambridge University Press.

Bayer, U.C. and Gollwitzer, P.M. (2005) Mindset effects on information search in selfevaluation. European Journal of Social Psychology, 35, 313-327.

Bobrow, D.G. and Winograd, T. (1977) An overview of KRL: A knowledge representation language. Cognitive Science, 1, 3-46.

Brandstätter, V. and Frank, E. (2002) Effects of deliberative and implemental mindsets on persistence in goal-directed behavior. Personality and Social Psychology Bulletin, 28, 1366-1378.

Brehm, J.W. and Cohen, A.R. (1962) Explorations in Cognitive Dissonance. New York: Wiley.

Brewer, M.B. (1988) A dual process model of impression formation. In T.K. Srull and R.S. Wyer (eds), Advances in Social Cognition, 1, 1-36. Hillsdale, NJ: Erlbaum.

Brickenkamp, R. (1981) Test d2, 7th Edition. Goettingen: Hogrefe.

Burgess, P.W., Simons, J.S., Dumontheil, I. and Gilbert, S.J. (2005) The gateway hypothesis of rostral PFC function. In J. Duncan, L. Phillips, and P. Mcleod (eds) Measuring the Mind: Speed Control and Age, pp. 215-246. Oxford: Oxford University Press.

Chaiken, S., Liberman, A. and Eagly, A.H. (1989) Heuristic and systematic information processing within and beyond the persuasion context.
In J.S. Uleman and J.A. Bargh (eds), Unintended Thought, pp. 212-252. New York: Guilford Press.

Christiansen, S., Dettingen, G., Dahme, B. and Klinger, R. (2010) A short goal-pursuit intervention to improve physical capacity: A randomized dinical trial in chronic back pain patients. Pain, 149 444-452.

Colvin, C.R. and Block, J. (1994) Do positive illusions foster mental health?: An examination of the Taylor and Brown formulation. Psychological Bulletin. $116,3-20$.

Fazio, R.H. (1990) Multiple processes by which attitudes guide behavior: The MODE model as an integrative framework. In M.P. Zanna (ed.), Advances in Experimental Social Psychology, 23, 75-109. San Diego: Academic Press.

Feather, N.T. and Newton, J.W. (1982) Values, expectations, and the prediction of social action: An expectancy-valence analysis. Motivation and Emotion, 6, 217-244.

Fiske, S.T. and Neuberg, S.L. (1990) A continuum of impression formation, from category-based to individuating processes: Influences of information and motivation on attention and interpretation. Advances in Experimental Social Psychology, 23, $1-73$.

Freitas, A.L., Gollwitzer, P.M. and Trope, Y. (2004) The influence of abstract and concrete mindsets on anticipating and guiding others' self-regulatory efforts. Journal of Experimental Social Psychology, 40, 739-752.

Fujita, K., Gollwitzer, P.M. and Oettingen, G. (2007) Mindsets and preconscious open-mindedness to incidental information. Journal of Experimental Social Pychology, 43, 48-61.

Gagné, F.M. and Lydon, J.E. (2001a) Mindset and relationship illusions: The moderating effects of domain specificity and relationship commitment. Personality and Social Psychology Bulletin, 27, 1144-1155.

Gagné, F.M. and Lydon, J.E. (2001b) Mindset and close relationships: When bias leads to (in)accurate predictions. Journal of Personality and Social Psychology, 81, 85-96.

Galinsky, A.D. and Moskowitz, G.B. (2000) Counterfactuals as behavioral primes: Priming the simulation heuristic and consideration of alternatives. Journal of Experimental Social Psychology, 36, 384-409.

Gilbert, D.T. (1989) Thinking lightly about others: Automatic components of the social inference process. In J.S. Uleman and J.A. Bargh (eds), Unintended Thought, pp. 189-211. New York: Guilford Press. 
Gilbert, D.T. and Malone, P.S. (1995) The correspondence bias. Psychological Bulletin, 117, 21-38.

Gilbert, S.J., Gollwitzer, P.M., Cohen, A-L., Oettingen, G. and Burgess, P.W. (2009) Separable brain systems supporting cued versus self-initiated realization of delayed intentions. Journal of Experimental Psychology: Learning, Memory, and Cognition, 35, 905-915.

Gollwitzer, P.M. (1987) Motivationale vs, volitionale BewuBtseinslage. (Motivational vs. volitional mindset.) Habilitationsschrift, Ludwig-MaximiliansUniversität München.

Gollwitzer, P.M. (1990) Action phases and mindsets. In E.T. Higgins and R.M. Sorrentino (eds), Handbook of Motivation and Cognition: Foundations of Social Behavior, 2, 53-92. New York: Guilford Press.

Gollwitzer, P.M. (1991) Abwägen und Planen: Bewußtseinslagen in verschiedenen Handlungsphasen (Deliberating and planning: Mindsets in different action phases). Goettingen: Hogrefe.

Gollwitzer, P.M. (1993) Goal achievement: The role of intentions. European Review of Social Psychology, 4, 141-185.

Gollwitzer, P.M. (1999) Implementation intentions: Strong effects of simple plans. American Psychologist, 54, 493-503.

Gollwitzer, P.M. and Bayer, U.C. (1999) Deliberative and implemental mindsets in the control of action. In S. Chaiken and Y. Trope (eds), Dual-process Theories in Social Psychology, pp. 403-422. New York: Guilford Press.

Gollwitzer, P.M., Gawrilow, C. and Oettingen, G. (2010) The power of planning: Effective selfregulation of goal striving. In $\mathrm{R}$. Hassin, K. Ochsner, and $Y$. Trope (eds), Self-control in Society, Mind, and Brain, pp. 279-296. New York: Oxford University Press.

Gollwitzer, P.M., Heckhausen, H. and Steller, B. (1990) Deliberative and implemental mindsets: Cognitive tuning toward congruous thoughts and information. Journal of Personality and Social Psychology, 59, 1119-1127.

Gollwitzer, P.M. and Kinney, R.F. (1989) Effects of deliberative and implemental mindsets on illusion of control. Journal of Personality and Social Psychology, 56, 531-542.

Gollwitzer, P.M. and Kirchhof, O. (1998) The willful pursuit of identity. In J. Heckhausen and C.S. Dweck (eds), Life-span Perspectives on Motivation and Control, pp. 389-423. New York: Cambridge University Press.

Gollwitzer, P.M. and Oettingen, G. (2011) Planning promotes goal striving. In K.D. Vohs and
R.F. Baumeister (eds), Handbook of Self-regulation: Research, Theory, and Applications, 2nd Edition, pp. 162-185. New York: Guilford Press.

Gollwitzer, P.M. and Sheeran, P. (2006) Implementation intentions and goal achievement: A meta-analysis of effects and processes. Advances in Experimental Social Psychology, 38, 69-119.

Gollwitzer, P.M., Sheeran, P., Michalski, V. and Seifert, A.E. (2009) When intentions go public: Does social reality widen the intention-behavior gap? Psychological Science, 20, 612-618.

Greenwald, A.G. and Banaji, M.R. (1995) Implicit social cognition: Attitudes, self-esteem, and stereotypes. Psychological Review, 102, 4-27.

Harmon-Jones, C., Schmeichel, B.J. and HarmonJones, E. (2009) Symbolic self-completion in academia: Evidence from department web pages and email signature files. European Journal of Experimental Social Psychology, 39, 311-316.

Harmon-Jones, E. and Harmon-Jones, C. (2002) Testing the action-based model of cognitive dissonance: The effect of action orientation on postdecisional attitudes. Personality and Social Psychology Bulletin, 28, 711-723.

Heckhausen, H. (1977) Achievement motivation and its constructs: A cognitive model. Motivation and Emotion, 4, 283-329.

Heckhausen, H. (1987) Wünschen - Wählen - Wollen. In H. Heckhausen, P.M. Gollwitzer, and F.E. Weinert (eds), Jenseits des Rubikon. Der Wille in den Humanwissenschaften (Crossing the Rubicon: The concept of will in the life sciences), pp. 3-9. Berlin: Springer Verlag.

Heckhausen, H. and Gollwitzer, P.M. (1987) Thought contents and cognitive functioning in motivational versus volitional states of mind. Motivation and Emotion, 11, 101-120.

Henderson, M.D., de Liver, Y. and Gollwitzer, P.M. (2008) The effects of implemental mindset on attitude strength. Journal of Personality and Social Psychology, 94, 394-411.

Higgins, E.T. and Sorrentino, R.M. (1990) (eds) The Handbook of Motivation and Cognition: Foundations of Social Behavior, Vol. 2. New York: Guilford Press.

Kappes, A. and Oettingen, G. (2011) From wishes to goals: Mental contrasting connects future and reality. Submitted for publication.

Külpe, 0. (1904) Versuche über Abstraktion (Experiments on abstraction). Bericht über den 1. Kongreß für experimentelle Psychologie, pp. 56-68. Leipzig: Barth.

Kuhl, J. (1984) Volitional aspects of achievement motivation and learned helplessness: Toward a 
comprehensive theory of action control. In B.A. Maher (ed.), Progress in Experimental Personality Research, 13, 99-171. New York: Academic Press.

Ledgerwood, A., Liviatan, I. and Carnevale, P.J. (2007) Group-identity completion and the symbolic value of property. Psychological Science, 18, $873-878$.

Lewin, K. (1926) Vorsatz, Wille und Bedürfnis (Intention, will, and need). Psychologische Forschung, 7, 330-385.

Liberman, N. and Trope, Y. (2008) The psychology of transcending the here and now. Science, 322, 1201-1205.

Marbe, K. (1915) Zur Psychologie des Denkens (The psychology of reasoning). Fortschritte der Psychologie und ihre Anwendungen, 3, 1-42.

Mischel, W. (1974) Processes in delay of gratification. Advances in Experimental Social Psychology, 7. 249-292.

Mischel, W. and Patterson, C.J. (1978) Effective plans for self-control in children. Minnesota Symposia on Child Psychology, 11, 199-230.

Norman, D.A. and Bobrow, D.G. (1979) Descriptions: An intermediate stage in memory retrieval. Cognitive Psychology, 11, 107-123.

Oettingen, G., Pak, H. and Schnetter, K. (2001) Selfregulation of goal-setting: Turning free fantasies about the future into binding goals. Journal of Personality and Social Psychology, 80, 736.

Oettingen, G. and Gollwitzer, P.M. (2010) Strategies of setting and implementing goals: Mental contrasting and implementation intentions. In J.E. Maddux and J.P. Tangney (eds), Social Psychological Foundations of Clinical Psychology, pp. 114-135. New York: Guilford Press.

Oettingen, G. and Stephens, E.J. (2009) Fantasies and motivationally intelligent goal setting. In G.B. Moskowitz and H. Grant (eds). The Psychology of Goals, pp. 153-178. New York: Guilford Press.

Orth, J. (1903) Gefühl und BewuBtseinslage: Eine kritisch-experimentelle Studie (Feelings and mindsets: An experimental study). In T. Ziegler and T. Ziehen (eds), Sammlung von Abhandlungen aus dem Gebiet der Pädagogischen Psychologie und
Physiologie, 4, 225-353. Berlin: Verlag von Reuter and Reichard.

Pösl, I. (1994) Wiederaufnahme unterbrochener Handlungen: Effekte der Bewusstseinslagen des Abwägens und Planens (Mindset effects on the resumption of disrupted activities). Unpublished master's thesis, University of Munich, Germany.

Puca, R.M. (2001) Preferred difficulty and subjective probability in different action phases. Motivation and Emotion, 25, 307-326.

Stadler, G., Oettingen, G. and Gollwitzer, P.M. (2009) Physical activity in women. Effects of a selfregulation intervention. American Journal of Preventive Medicine, 36, 29-34.

Stadler, G., Oettingen, G. and Gollwitzer, P.M. (2010) Intervention effects of information and selfregulation on eating fruits and vegetables over two years. Health Psychology, 29, 274-283.

Taylor, S.E. and Armor, D.A. (1996) Positive illusions and coping with adversity. Journal of Personality, 64, 873-898

Taylor, S.E. and Brown, J.D. (1988) Illusion and well-being: A social psychological perspective on mental health. Psychological Bulletin, 103. 193-210.

Taylor, S.E. and Gollwitzer, P.M. (1995) The effects of mindsets on positive illusions. Journal of Personality and Social Psychology, 69, 213-226.

Taylor, S.E., Kemeny, M.E., Reed, G.M., Bower, J.E. and Gruenewald, T.L. (2000) Psychological resources, positive illusions, and health. American Psychologist, 55, 99-109.

Watt, H.J. (1905) Experimentelle Beiträge zu einer Theorie des Denkens (Experimental analyses of a theory of reasoning). Archiv für die gesamte Psychologie, 4, 289-436.

Weinstein, N.D. (1984) Why it won't happen to me: Perception of risk factors and susceptibility. Health Psychology, 3, 431-457.

Wicklund, R.A. and Gollwitzer, P.M. (1982) Symbolic Self-completion. Hillsdale, NJ: Erlbaum.

Wong, E.M., Galinsky, A.D. and Kray, L.J. (2009) The counterfactual mindset: $A$ decade of research. In K.D. Markman, W.M.P. Klein, and J.A. Suhr (eds), Handbook of Imagination and Mental Simulation, pp. 161-174. New York: Psychology Press. 